\title{
Smart home technology-comparing householder expectations at the point of installation with experiences 1 year later
}

\author{
Luis Oliveira $^{1}$ (D) $\cdot$ Val Mitchell ${ }^{2} \cdot$ Andrew May $^{2}$ \\ Received: 28 February 2019 / Accepted: 20 August 2019 / Published online: 6 September 2019 \\ (C) The Author(s) 2019
}

\begin{abstract}
This study, with 19 households, set out to analyse the expected benefits and anticipated challenges to the introduction of smart home technology (SHT), and to compare these to post-use experiences after living with the technology for 1 year. Contextual interviews were undertaken with householders during the installation of a range of SHT, and again approximately 1 year later, when householders had the option to keep the technology or have some or all of it removed. This identified whether initial expectations were met, whether initial concerns persisted and whether new issues, concerns, and benefits (that had not been initially anticipated) arose after an extended period of use. Initial expectations from all households were high — related to comfort, convenience, improved control, energy demand reduction, and integration of technologies. There were also many initial concerns, including reliability, usability, and how these systems would be 'domesticated' to fit existing routines. After living with the systems for 1 year, many expectations were met, but the added value (and hence the match between expectations and reality) was higher for households with varied routines and large, partially occupied houses. Some of the anticipated challenges - such as concerns over aesthetics-largely disappeared, issues to do with the awkward location of network components persisted and new issues arose relating to the usability of some components and the time and effort required to configure them. Recommendations are given to maximise the added value that SHT can provide to householders.
\end{abstract}

Keywords Smart home technology $\cdot$ Field study $\cdot$ User-centred design $\cdot$ Domestic sector $\cdot$ Energy saving $\cdot$ Longitudinal study

\section{Introduction}

\subsection{Background}

The notion of the smart home has been well established since the 1990s [1]. A 'Smart Home' utilises information and communication technologies either internal or external to the home to enable remote monitoring, automation, and control

Luis Oliveira

1.oliveira@Warwick.ac.uk

Val Mitchell

v.a.mitchell@1boro.ac.uk

Andrew May

a.j.may@lboro.ac.uk

WMG, University of Warwick, Coventry, UK

2 Design School, Loughborough University, Loughborough, UK of appliances and services. An increasing number of householders are interested in the comfort, convenience, security, energy saving, and assisted living that a smart home can provide [2-4].

Smart homes are seen as a key opportunity to reduce the levels of energy demand within domestic housing. As much of today's housing stock is expected to exist for many years, the widespread adoption of smart home technology (SHT) as a means to reduce energy demand is dependent on its successful retrofitting into existing homes. Integration into existing domestic homes, however, continues to be piecemeal with two of the prevailing barriers to adoption recognised as the lack of understanding of user needs [1] and difficulties associated with retrofitting smart products and services into existing housing stock $[5,6]$. The integration of technology into homes generally happens in increments, building on the existing structural and technological layers of a house [7]. Tolmie et al. [8] underline that it is necessary to 'respect existing technological arrangements in the home and make new installations fit in with them', and it is especially important to 
consider the potential for disruption caused by more technology [9].

\subsection{Consumer uptake of smart home technology}

As highlighted by previous reviews $[6,10,11]$, there has been a longstanding tendency for smart home research to focus on technical feasibility. However, there is a growing body of research that takes a more user-driven perspective to understand the barriers and enablers to the uptake of SHT.

Wilson et al. [4], in a national survey, highlighted that prospective users perceived there to be a range of benefits from smart homes, including saving energy, time, and money, and reducing the effort associated with domestic life. However, they also showed that prospective users saw a range of potential risks with smart homes, including increasing dependence on technology, energy networks, and external 'experts'. These findings are in line with those of Balta-Ozkan et al. [2].

In order to investigate the issues surrounding the installation of SHT, it is desirable to undertake a longitudinal form of study, where both changes in attitudes and actual relevant behaviours are investigated. It is well accepted that users form judgments about a system that may be modified over time [12]. If observations are taken only at a specific point in time, 'user experience evaluations may reflect more users' expectations than actual experiences' [13]. In particular, user experience is dynamic and changes over time; therefore, research in human-computer interaction should give more attention to the study of changes over longer periods of time [14]. A good example of the need for longitudinal studies of behaviours is an investigation of technology in the home by Venkatesh and Brown [15]. Having determined householders' intentions in relation to buying new technology, they resampled 6 months later and found very mixed relationships between initial consumer attitudes and intentions, and what consumers actually did some time later. Hargreaves et al. [16] undertook a longitudinal study of how households learn to use and adapt to SHT. They described how SHT can be disruptive within a household, require adaptation and familiarisation, and also pose a challenge in terms of learning how to use them. They also question whether smart homes would actually deliver promised energy savings. There has also being research about the introduction of SHT and how it can affect the internal relations of power and control within families $[17,18]$.

Despite increasing attention to the situated and longer-term investigation, there has been relatively little study of the expectations and issues that arise during installation from a householder perspective, or the impact these issues have upon subsequent acceptance or rejection of the technologies in smart homes. A recent exception to this is [9] who identify some of the challenges that arise when deploying technology in the home. This lack of study of the expectations that arise during installation, and follow up, is despite the initial perceptions (including the 'out of the box' experiences) being recognised as a key factor influencing adoption and future use of technology [19]. Initial perceptions of the usefulness and purpose of technologies will often be formed at the earliest touchpoints, impacting on how they are then domesticated into everyday life [16]. A better understanding of SHT at this very early point of engagement can inform the design of products, consumer advice, and the training of relevant professionals to encourage wider uptake of SHT into existing homes.

\subsection{Aims}

This paper reports on a study carried out as part of a UK Smart Home trial, focusing specifically on the relationship between the initial expectations and post-experience reality. The aims of this research were, firstly, to determine the expectations of benefits and anticipated challenges at the installation phase of SHT. Secondly, the study determined whether the householders' views in relation to these expectations and challenges were maintained after they had lived with the technology for approximately 1 year, and had the choice to either keep the technology or have it removed.

\section{Method}

\subsection{The smart home technology deployed}

This study was undertaken as part of the REFIT project ${ }^{1}$, a multidisciplinary research initiative investigating the use of SHT in UK homes, with a particular emphasis on energy demand reduction. The project conducted a field study of 2 $1 / 2$ years total duration and deployed SHT in a sample of 20 dwellings. RWE Smarthome ${ }^{\mathrm{TM}}$ devices $^{2}$ were fitted within each home to provide heating system management, allow zonal thermal control, and provide home security features. The devices included one central controller and several batteryoperated remote units. A typical installation comprised nine radiator thermostats with temperature and air humidity sensor, three room thermostats to control radiators in a particular room or zone, six indoor and one outdoor motion detectors with integrated brightness sensor, door and window contact sensors to record opening and closing events, one smoke detector and alarm, two wall-mounted transmitters working as physical switches to trigger actions, and one remote control providing eight buttons which could be configured to control devices in the RWE system. Additional devices include ZWave Vera ${ }^{\mathrm{TM}}$ controllers $^{3}$ linked to smart plugs to give remote

\footnotetext{
${ }^{1}$ http://www.refitsmarthomes.org/

2 https://www.rwe-smarthome.de/

${ }^{3}$ http://getvera.com/
} 
and automated control over selected appliances and Current Cost units ${ }^{4}$ to monitor electricity consumption. British Gas Hive Active Heating system ${ }^{5}$ was also offered to provide advanced control of boilers, and it was subsequently installed in 15 homes that agreed to have this technology.

\subsection{Household compositions}

The sampling strategy set out to identify householders with a range of houses typical of those in the UK, including older properties where energy-saving measures have to be retrofitted. To counter the natural tendency for field trials to involve the 'very engaged', recruitment attempted to balance technology experienced and inexperienced households. This was only partially effective, as the final sample consisted of $n=14$ households where at least one of the adults self-declared themselves as experienced and $n=6$ inexperienced. In addition, the presence of children in the household has been shown to influence the dynamics of energy consumption [18]. The final household sample consisted of $n=10$ families with and $n=10$ without children living at home (Table 1). Households were recruited via mailing lists and posters distribute locally around Loughborough, UK.

From the 20 households participating in the project, due to availability, only 17 were interviewed before the installation of the equipment and 19 during the second round of visits. House 14 dropped out in the early stages of the research and was replaced by house 21. It was not possible to visit house 13 in either of the phases, so this household did not contribute to this specific study.

\subsection{Data collection pre- and post-experience}

The initial data collection (termed 'pre-installation') was undertaken with householders in the summer of 2014 when they were being introduced to the SHT for the first time. During this visit, the technologies and their installation in the home were discussed with the householders. The purpose of this home visit within the field trial was to enable the householders to decide which technologies they wanted installing in their homes and where specific items would be situated. Similarly to [20], the installation of the SHT comprised a process of negotiation with householders, who had the final say over installation so they could opt out of any of the devices and choose where technology was installed. Rather than a traditional face-to-face interview, the data collection in the study took the form of a contextual enquiry with householders including a tour of the house to define locations of equipment.

\footnotetext{
${ }^{4}$ http://www.currentcost.com/

5 https://www.hivehome.com/
}

Table 1 Demographics

\begin{tabular}{|c|c|c|c|c|c|c|}
\hline \multirow[b]{2}{*}{ No. } & \multicolumn{2}{|c|}{ Data collection } & \multirow[t]{2}{*}{ No. of residents } & \multicolumn{2}{|c|}{ Adults' ages } & \multirow[t]{2}{*}{ Child ages } \\
\hline & Pre- & Post- & & Male & Female & \\
\hline 1 & $\bullet$ & $\bullet$ & 2 & 65 & 63 & \\
\hline 2 & $\bullet$ & $\bullet$ & 4 & 34 & 36 & $2,1 / 2$ \\
\hline 3 & $\bullet$ & $\bullet$ & 2 & 64 & 69 & \\
\hline 4 & $\bullet$ & $\bullet$ & 2 & 64 & 65 & \\
\hline 5 & $\bullet$ & $\bullet$ & 4 & 51 & 47 & 12,10 \\
\hline 6 & $\bullet$ & $\bullet$ & 2 & 54 & 59 & \\
\hline 7 & $\bullet$ & $\bullet$ & 4 & 44 & 41 & 5,1 \\
\hline 8 & $\bullet$ & $\bullet$ & 2 & 79 & 72 & \\
\hline 9 & & $\bullet$ & 2 & 62 & 59 & \\
\hline 10 & $\bullet$ & $\bullet$ & 4 & 43 & 41 & 7,4 \\
\hline 11 & $\bullet$ & $\bullet$ & 1 & - & 71 & \\
\hline 12 & & $\bullet$ & 2 & 58 & 54 & \\
\hline 15 & $\bullet$ & $\bullet$ & 1 & - & 45 & \\
\hline 16 & & $\bullet$ & 6 & 50 & 40 & $19,18,16,14$ \\
\hline 17 & $\bullet$ & $\bullet$ & 3 & 62 & 59 & 17 \\
\hline 18 & $\bullet$ & $\bullet$ & 2 & 73 & 71 & \\
\hline 19 & $\bullet$ & - & 4 & 43 & 48 & 11,8 \\
\hline 20 & $\bullet$ & $\bullet$ & 2 or 3 & 58 & 55 & 22 \\
\hline 21 & $\bullet$ & $\bullet$ & 4 & 33 & 43 & 11,9 \\
\hline
\end{tabular}

When possible, all family members took part in the discussion.

The second set of interviews took place during the summer of 2015. These were undertaken during a home visit to determine whether householders wanted to keep any/all of the systems and to collect all remaining monitoring equipment. By capturing data at the point where households were potentially choosing to either keep or have removed the systems, the 'actual behaviours' aspect — c.f. Venkatesh and Brown [15]—-is being targeted. The explicit decisions about installation (based on expectations) were therefore mirrored by the householders' decisions to keep or reject the technology based on whether those expectations had been met or other issues had arisen.

The post-experience interviews for each household were tailored according to the issues that had been raised at the pre-installation phase - i.e. they were designed to specifically address the expectations and challenges that had been posed at the outset by that individual household. For the three households interviewed only at the post-experience phase $(9,12$, and 16), a summary of the most frequently pre-installation expectations and challenges raised by other participants was used as the basis for enquiry for these households.

\subsection{Coding strategy}

The interviews generated a total of 31 hours of recording. Following transcription, they were coded and 
analysed by theme [21]. The initial themes that emerged from the interviews fell into categories matching an existing organising framework developed by Wilson et al. [6] and modified by Oliveira et al. [22]. This framework contemplates both the expectations people hold about the potential benefits and the anticipated challenges from the technology. The expectations are divided into three narratives for smart home research: functional (to deliver a better living such as comfort or convenience), instrumental (reduce consumption, bills, emissions), and socio-technical (appropriation of technology into everyday life). Additionally, the framework describes three challenges for realising the benefits of the smart home: hardware and software, acceptability and usability, and domestication of technology. Frameworks are instrumental for indexing and sorting data instead of trying to create theory from the ground up [23]. The data in this study was generated in a bottom-up approach using open-ended contextual enquiry; the framework [6] was used to map the findings according to the impact categories that had been identified previously as relevant for SHT.

\section{Results}

\subsection{Were householders' initial expectations met?}

Table 2 shows the key expectations of benefits that householders held before the introduction of the technology into their homes (left-hand column), based on the framework from Wilson et al. [6]. The reality after 1 year's use is shown in the right-hand column. Based on those households which stated a particular expectation, where the majority stated their initial expectations were met, the theme is marked with a green tick $(\nabla)$. Where the majority of householders' expectations were not met in relation to a particular issue, this is indicated with a red cross (匈). If a clear conclusion could not be reached, either due to diverse findings or lack of data, this is indicated with [?].

\subsection{Functional benefits}

During the pre-installation visits, householders acknowledged the range of potential benefits offered by smart technology within the home. These included the functional aspects of convenience, comfort, and practicalities such as fine control of temperatures in rooms and zones, remote control of the heating system and lights, and improved security. During the second visit, the male participant from house 3 (MH3) stated: 'I'm very pleased with [Hive] because in having had it fitted, I am able to control, from my laptop, every day of the week, exactly what we need. And we've adjusted it, we've finetuned it, and it's worked fine'. The technology improved control and facilitated the access to difficult-to-reach radiators and for less-abled individuals, as the female from house 11 mentioned (FH11): 'I did get used to it and realised just how useful it was for changing the radiator valve in the back bedroom, which is very hard to get at manually.... Basically, I had to be on my stomach with a torch to see what the radiator valve said... Now I use the computer, I don't have to do anything with the radiator valves.' (Fig. 1).

The SHT also provided the expected zonal control, as a way of providing different heat profiles for children in separated rooms: 'So one of them wants it much hotter than the other' (FH21). The remote control of the heating system was achieved by six householders who wanted this feature, for example, to monitor temperatures when away during winter, or to pre-warm the house when returning from holidays. However, control of lights and appliances by households was limited, not meeting their initial expectations, and some users had expectations beyond the capability of the systems installed: 'We've not been able to have the porch light going on and off or the kitchen lights coming on and off as we go through the room or something like that, which is kind of what I thought it would be nice if it did' (MH10).

Although window contacts were installed, the expectations regarding enhanced safety and security were not met, mainly because the installed systems were not purposely built security systems. MH5 stated: 'There's no point having a homemade security system, you need a security system that's provided by a reputable alarm system company. So while they're interesting, they're economically and practically useless'. The couple in H10 commented that there was not much they could do if they were away and were alerted that a door or window had been opened: 'Well, you know, the most we could do if somebody were to break in would be to turn a radiator on! [laughs]' The smoke detector was connected wirelessly to the central unit and could send messages or emails if the alarm went off. One participant complained that the notification arrived a few minutes after the event (MH3), and one couple was away on holidays and received an automated email saying that the smoke alarm had gone off in their house. They had to call the fire brigade to ask if their house had gone up in smoke. 'But it turned out the battery had gone!' (FH9).

\subsection{Instrumental benefits}

Other expectations voiced by our householders regard the instrumental (i.e. save energy, save money, sustainability) aspects of smart homes, when technology works as a tool to reduce energy use and costs. Participants believed they reduced energy use through the optimisation of the heating system-heating specific rooms to set 
Table 2 Initial expectations and whether these were met: $\square$ expectation met; $\boldsymbol{x}$ expectation not met; [?] mixed view

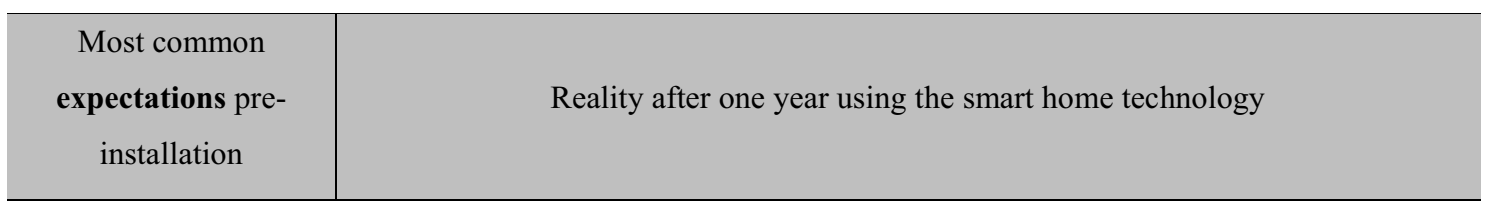

Functional

\begin{tabular}{|c|c|}
\hline $\begin{array}{l}\text { Increase comfort and } \\
\text { convenience }\end{array}$ & $\begin{array}{l}\square 13 \text { households had managed to gain convenience from the systems installed and } \\
\text { could now perform certain tasks with less effort and difficulty, although some } \\
\text { inconveniences had emerged }\end{array}$ \\
\hline $\begin{array}{l}\text { Fine control of } \\
\text { temperature in rooms } \\
\text { and zones }\end{array}$ & $\begin{array}{l}\square 15 \text { households reported achieving better control of heating in terms of space and } \\
\text { time to better match occupation, and some had configured advanced triggers }\end{array}$ \\
\hline $\begin{array}{l}\text { Control of heating } \\
\text { remotely }\end{array}$ & $\begin{array}{l}\square 6 \text { households with smartphones were happy with remote access and control, } \\
\text { reporting that they used it on different occasions } \\
\text { 囚 Other households did not have smartphones (3) or couldn't see the need for remote } \\
\text { control (7) }\end{array}$ \\
\hline $\begin{array}{l}\text { Control of lights and } \\
\text { sockets }\end{array}$ & $\begin{array}{l}\text { ⿴囗十 } 17 \text { households were unable to control the lights remotely due to the difficulty of use } \\
\text { of the software and the provision of socket switches only }\end{array}$ \\
\hline $\begin{array}{l}\text { Enhance security and } \\
\text { safety, monitor } \\
\text { intruders and } \\
\text { occupants, fire alarm }\end{array}$ & $\begin{array}{l}\text { ⿴囗 } 6 \text { households used the systems to simulate occupancy or to check if windows and } \\
\text { doors were left open, but recognized that the installed system was not a bespoke } \\
\text { security system, and therefore would not deter intruders } \\
\text { ख The installed fire alarms worked as regular smoke sensors but the added features } \\
\text { such as email and message notifications proved unreliable }\end{array}$ \\
\hline
\end{tabular}

\section{Instrumental}

\begin{tabular}{l|l}
\hline $\begin{array}{l}\text { Reduce energy use and } \\
\text { costs }\end{array}$ & $\begin{array}{l}\text { [?] } 7 \text { participants believe they reduced energy use via zone control and time } \\
\text { optimisation. However, most of the households could not attribute savings to the } \\
\text { technology due to seasonal variation, occupancy changes, other simultaneous home } \\
\text { improvements, or due to simply not monitoring expenses }\end{array}$ \\
$\begin{array}{l}\text { View data on energy } \\
\text { use }\end{array}$ & $\begin{array}{l}\square 14 \text { households managed to visualise and make sense of energy use in diverse forms, } \\
\text { for example, the electricity base load (5), disaggregated energy use per monitored } \\
\text { appliances (6), and temperatures in individual rooms (14) }\end{array}$ \\
\hline
\end{tabular}

\section{Socio-technical}

Be up to date with technology, learn, engage $\square 10$ households indicated that the introduction of technology motivated new efficient behaviours (5), brought their homes more up to date (4) and encouraged them to search for additional SHT and efficient appliances (3) 冈 Children did not engage with the systems as expected due to lack of interest (3) or parents centralising the control (2) 


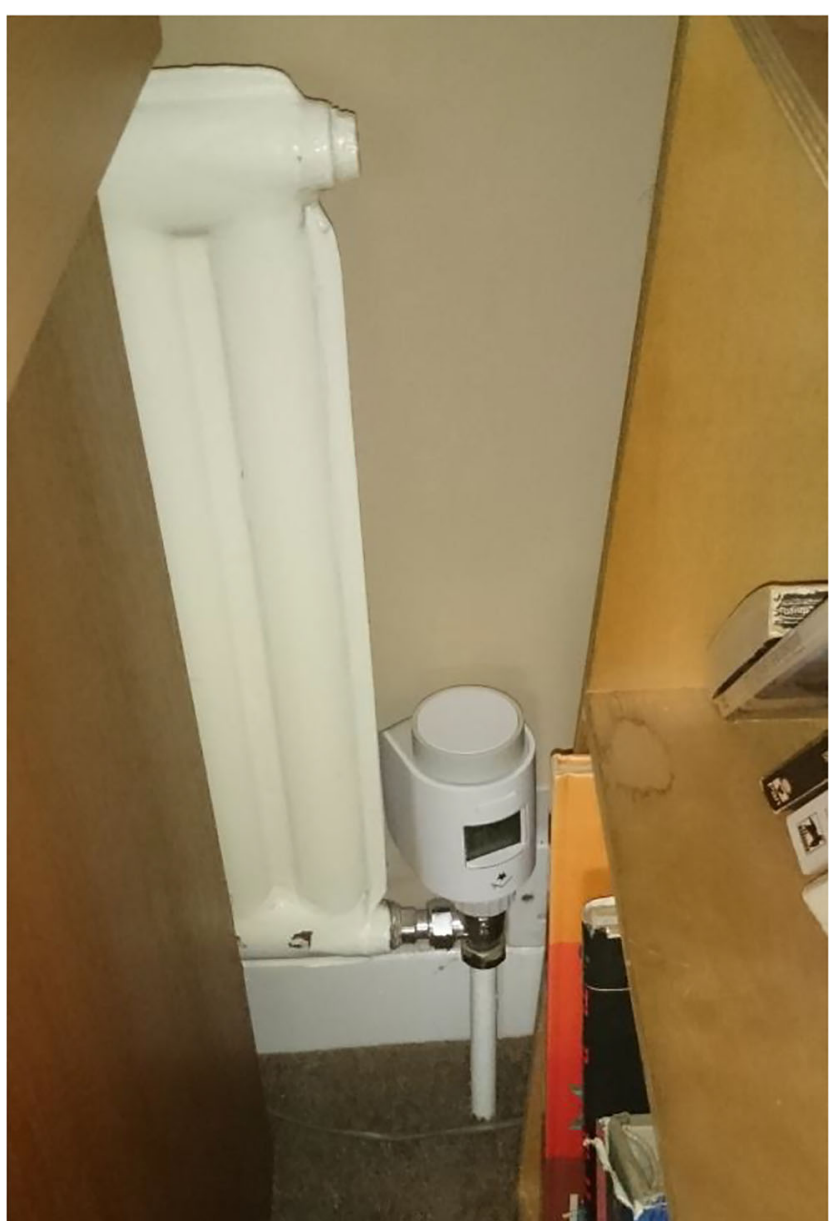

Fig. 1 Providing access to inaccessible controls

temperatures at particular times. However, they could not specify the savings. MH6 described: 'we must be saving money because we're only heating the rooms we want to heat, to the temperature we want to heat them to'. However, he acknowledged that the actual energy savings from before and after the introduction of the SHT were difficult to measure: 'to be honest it's difficult to predict because it's so dependent on things like outside temperature, because if it's not been as cold outside, how do you know if you've actually saved money?'.

Householders also obtained the expected real-time feedback on electricity consumption and heat output. MH1 reported that he could monitor details of the energy use in his house: 'if I'm sat at the desktop computer, the thing's right next door, I can see exactly what's working and what's consuming power. If [wife] suddenly starts cooking, I can see that she's you know started cooking or using the washing machine or dishwasher'. H16 adds that having the energy monitor motivated actual behaviour change: 'I have consciously looked around to see what I can turn off more often'.

\subsection{Socio-technical benefits}

One final category of householder expectations is related to the socio-technical aspects of smart homes. Participants wanted to modernise their houses but also to learn and be up to date with technology itself. In particular, families wanted to engage children with technology in the early stages of development and commercialisation. However, the levels of involvement with the technology reflected or reinforced existing exclusions. MH17 explained that his wife 'leaves it for me to do! [She] is terrified with anything technical... that needs understanding how to operate it'. It was observed that the involvement of children was limited, either due to lack of interest or parents centralising the control: 'the girls are old enough to be on their own at home, but they don't actually have access to the thermometer controls... [Wife] and I will be at work, and they can ring us up and say 'the house is a bit cold Dad', 'alright, I'll just turn it up a bit from here', you know, that's weird but that's what will happen' (MH5). FH19 also explained that she had to take control of the systems due to their circumstances: 'it's really been me operating it because my husband works away a lot of the time and the kids, although they were interested to start with, haven't really taken an interest in it'.

\subsection{Were anticipated challenges overcome by households?}

Table 3 summarises the key anticipated challenges, barriers, or issues that were raised by householders before the introduction of the technology into their homes. As above, the challenges were classified according to the framework adapted from Wilson et al. [6]. It shows, in the right column, whether challenges that had been raised at the pre-installation phase had been somehow overcome or turned out not to be the case as initially anticipated, marked with a green tick $(\nabla)$. The table also shows if these challenges persisted or became aggravated, marked in red (匈), after they had used the technology for about 1 year.

\subsection{Hardware and software challenges}

All households raised concerns in the pre-installation interviews that their existing house infrastructure would prevent the smooth introduction of the new technology. They were concerned over the compatibility of the new electronic valves with their existing radiators due to age, different fittings, shape, and available space. Indeed, some non-thermostatic valves had to be replaced, fittings with different threads needed adaptors or replacement, and a few radiators prevented the installation of the new, larger radiator valves altogether. MH1 explains: 'Yeah, we couldn't fit [the RWE radiator valves], I'd have to, you know actually dismantle some of the heating fins 
on the rads, I'd have to dismantle them, to pull them out from the wall, to be able to allow the valves to be fitted. That's just too big a job'. Drainage of the heating system was required in four homes. The age and condition of the existing boilers were initially also a concern. However, only one boiler was actually incompatible with the smart heating control Hive system.

Most of the hardware challenges were related to the wiring and locations of routers, and the number of available Ethernet ports and power sockets. Extensions, adaptors, and bridges were required in order to connect the new devices alongside existing technology. The position of routers and internet access points determined the location of RWE and Vera central units because these had to be connected directly to an Ethernet port. Therefore, the Current Cost energy feedback displays ended up installed where internet hubs were located, such as behind cabinets or under the stairs in five houses, making their use (and hence visualisation of energy consumption) inconvenient. When asked if it was easy to see the energy monitor, FH19 said 'well it is, if you're on your hands and knees looking in the cupboard! [laughs]'.

Participants had expectations that the smart technology would be unreliable and that devices would fail, and that there would be internet glitches and other teething problems. Several devices did fail and needed resetting or replacing, and a $\log$ of issues reported 17 visits to the trial households to sort out major problems such as central units not keeping time, faulty sockets, radiator valves giving error codes, and door sensors not communicating. Power cuts, internet failures, and households changing network providers also led to participants requesting assistance to put the system back in working order. Some of the failures were difficult to diagnose and still present during the final interview, as illustrated by FH8: 'It's just saying to me it's not connected to the hub. And I've looked at all the wires and I can't see anything disconnected ... I've crawled underneath, I've tried every connection there is, even things that don't belong to it, or I don't think belong to it, I've shoved them in and done absolutely everything and it ... it's still telling me that it's not connected to the hub. So I don't know what to do'.

During the pre-installation visit, when the devices were tested and functions demonstrated, a couple of households mentioned that the radiator valves were noisy. After living with the system for 1 year, eight households were still vocal about this issue. For example, H17 reported that 'suddenly you'll get a whirring noise that will go on for 20,30 seconds until it opens or closes to the requisite amount... So potentially it could affect sleep... it's not a quiet mechanism'. Participants also reported minor issues with the occupancy sensors when detecting movement: 'They're OK, it just, the only one that annoyed me was the one up on the landing window, when I went to the loo in the night, I had a bright green light winking at me' (FH18). MH1 comments that occupancy sensors can also be heard: 'I can hear the thing click, you know, because it's picked me up, picked up the movement'.

\subsection{Acceptability and usability challenges}

The further category of challenges to the introduction of SHT related to the acceptability and usability of the systems. Households anticipated that the technology would be difficult to understand and manage. It indeed turned out to be demanding from both ergonomic and cognitive viewpoints. Eleven households experienced difficulties with the systems' interfaces, labels, icons, logins, and device displays. Also, 14 households reported that the systems were difficult to understand and that dedicated time and effort was required to learn how to use them: 'I can see someone who has got pretty much nothing else to do with their lives, playing around with that all the time... I think it's too confusing for an average person to deal with' (MH9). Some participants deliberately used only the simpler features of the systems to minimise the required effort. FH11 stated that: 'I think the overall system still feels complicated to me, but I've learnt the bits that I need to do'. Similarly, MH20 commented: 'we're not really putting much of a demand on it... we're just using the very basic system'.

Acceptance and tolerance with the systems seemed to come with time, helped by the fact that users took into consideration the benefits obtained. For example, H12 had complained about the size of the new radiator valves: 'we thought we wouldn't keep them at the end of the project, we thought we'd go back to have the other ones put back on ... but actually, we find them really beneficial ... But if they were a bit smaller, then I think they would... look a bit nicer'.

Occasionally, participants chose to invest money, time, and/or effort in order to overcome what they saw as barriers to successful use of SHT. Two participants bought smartphones, eliminating a technological barrier mentioned during the pre-installation visit. H05 exemplified the level of dedication needed to configure the motion sensor to trigger the radiator valves in the living room to make sure it had heat whilst occupied: 'I am tenacious, I won't give up, so I got it to work but I don't think ... a person who wasn't a computer programmer would be bothered to do that ... it took me two or three weeks to get that working'.

During the initial installation phase, aesthetic concerns such as the obtrusiveness of the devices or the addition of 'clutter' to the house were mentioned widely (Fig. 2). In the exit interviews, householders explained that these issues were of less concern for three main reasons. Firstly, the devices faded into the background with time and occupants stopped noticing them: 'actually, after it's been in about two weeks, you forget it's there' (FH8). Secondly, the devices were 'amongst other objects' (MH1) and were not 
Table 3 Initial perceived challenges and whether they were overcome

\begin{tabular}{|c|c|}
\hline $\begin{array}{l}\text { Most common } \\
\text { challenges pre- } \\
\text { installation }\end{array}$ & Reality after one year using the smart home technology \\
\hline \multicolumn{2}{|r|}{ Hardware and software } \\
\hline $\begin{array}{l}\text { House structure, } \\
\text { existing hardware } \\
\text { compatibility }\end{array}$ & $\begin{array}{l}\square \text { Several perceived barriers regarding hardware compatibility turned out to not be the } \\
\text { case: the systems were successfully fitted to different house configurations alongside } \\
\text { diverse existing technologies } \\
\text { 囚 New valves didn't fit radiators in some houses so the project had to finance a } \\
\text { plumber to replace fittings } \\
\text { 囚 In } 5 \text { houses the location of routers and Ethernet ports meant that energy monitors } \\
\text { had to be installed out of sight, under stairs or behind cabinets } \\
\text { 囚 Some computers were unable to run the systems, needed software updates or } \\
\text { routinely crashed }\end{array}$ \\
\hline $\begin{array}{l}\text { Reliability, failure, } \\
\text { errors, malfunctions }\end{array}$ & $\begin{array}{l}\otimes 9 \text { households reported faulty devices that needed replacing } \\
凶 5 \text { households reported loss of communication between devices or the internet } \\
\text { System lag made settings doubtful for } 3 \text { participants }\end{array}$ \\
\hline $\begin{array}{l}\text { Devices rely on } \\
\text { batteries }\end{array}$ & $\begin{array}{l}\text { X } 7 \text { households reported that batteries died in radiator valves and needed replacing } \\
\text { during the course of the trial, and an additional } 4 \text { households expressed concerns about } \\
\text { the need to rely on batteries and the number of these required }\end{array}$ \\
\hline $\begin{array}{l}\text { Characteristics of } \\
\text { devices making them } \\
\text { noticeable }\end{array}$ & $\begin{array}{l}\otimes 8 \text { households complained that the motorised radiator valves were noisy } \\
\text { 冈 households mentioned that motion detectors flash or click } \\
\text { 冈 } 4 \text { households said radiator valves are big and obtrusive (2) and socket sensors bulky } \\
\text { (2) }\end{array}$ \\
\hline
\end{tabular}

noticed anymore. H16 commented that 'we've already got sensors for the burglar alarm, so it's not really an intrusion', and H2 stated: 'it's just another thing. I guess you can see them but it doesn't bother us'. Finally, having these devices in homes is not unusual nowadays, as H18 indicates: 'people expect to see things like that when they go into people's houses, 'oh you've got one of those!' [laughs]'.

\subsection{Challenges for domesticating technologies}

The final category of challenges to the introduction of SHT related to the domestication of technology. The systems were introduced into diverse environments, in real homes with existing dynamics and practices. Participants were concerned that the systems may not fit the way they manage their households and were sceptical of the prospect of the technology being able to support their routines and lifestyles. MH5 describes how his house (with a varied use of rooms) was subjected to rigorous programming to match heat and occupancy for two rooms in two ways: (1) when there is a pattern of use over times of the day and (2) when the occupancy is unpredictable:

'I've linked that movement sensor to these two radiators in here because this room is, it's not very predictable about its usage. The kitchen and the basement downstairs, the usage in those rooms is cyclic, you know, it's very predictable, go down in the morning, cook dinner, come up in the evening, go down in the morning, cook dinner, you know. So, I've set the radiators in there to have patterns... Whereas this room is a bit less predictable, so I use the movement sensor to trigger the radiators. So it's a combination of movement triggering and also a pattern'. 
continued

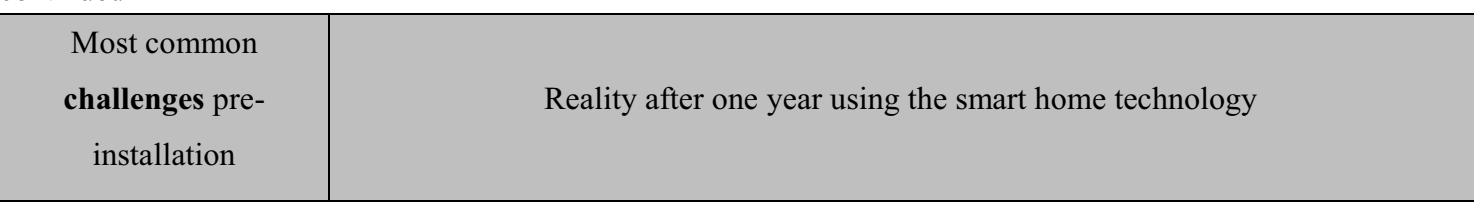

Acceptability and usability

\begin{tabular}{|c|c|}
\hline $\begin{array}{l}\text { Poor ergonomics and } \\
\text { user-friendliness }\end{array}$ & $\begin{array}{l}凶 11 \text { households experienced difficulties with the systems' interfaces, labels, icons, } \\
\text { logins and device displays } \\
\text { 冈 Valve displays were upside down for the majority of radiators due to being built for } \\
\text { the German market where the valves are generally horizontal }\end{array}$ \\
\hline $\begin{array}{l}\text { Difficult to understand, } \\
\text { time-consuming }\end{array}$ & $\begin{array}{l}\text { ⿴ } 14 \text { households reported that the systems were difficult to understand and confusing, } \\
\text { and that some dedicated time and effort was required to learn how to use them }\end{array}$ \\
\hline $\begin{array}{l}\text { Aesthetics and physical } \\
\text { presence of the devices }\end{array}$ & $\begin{array}{l}\square 13 \text { households declared that by the end of the field trial they were no longer } \\
\text { concerned about the aesthetics of the devices within their house - they faded into the } \\
\text { background or were less intrusive than other existing devices }\end{array}$ \\
\hline $\begin{array}{l}\text { Concerns about trust, } \\
\text { security and data } \\
\text { protection }\end{array}$ & $\begin{array}{l}\text { X Concerns about data security and protection persisted for the only } 2 \text { households that } \\
\text { had previously raised it }\end{array}$ \\
\hline
\end{tabular}

\section{Domesticating technologies}

\begin{tabular}{|c|c|}
\hline $\begin{array}{l}\text { How technology will fit } \\
\text { the messy nature of } \\
\text { everyday life }\end{array}$ & $\begin{array}{l}\square \text { Varied occupancy of the house or rooms, different daily schedules and/or large } \\
\text { houses allowed optimisation using the technology to result in energy use only when } \\
\text { needed } \\
\text { 冈 } 8 \text { households with regular routines or using all rooms of the house found it difficult } \\
\text { to justify the need for SHT since previous arrangements were satisfactory } \\
\otimes \text { Children, grandchildren and pets fiddled with the system in } 6 \text { houses }\end{array}$ \\
\hline $\begin{array}{l}\text { How householders } \\
\text { currently manage their } \\
\text { homes, the need for } \\
\text { technology to support } \\
\text { their routines }\end{array}$ & $\begin{array}{l}\text { Xarticipants with frugal lifestyles who already closely manage their energy use were } \\
\text { reluctant to adopt the technology }\end{array}$ \\
\hline
\end{tabular}

$\checkmark$ The perceived challenge did not materialise or was overcome

冈 Challenge persisted or worsened

FH15 made use of the advanced features of the Hive system to match her needs. She works different shift patterns and the possibility to turn the heating on and off remotely was used frequently.

'I can switch the heating on and off on my way home from work or when I'm going to work... whereas before I'd just go out and not think about it... I had a timer on my boiler but it was a manual timer, so you'd put it on and you know it would come on every day, but sometimes I wasn't in the house. But with the Hive and that, I could turn the heating off when I'm not in, without touching the boiler whatsoever... I've got it set with the geographical... marker, so if you're a mile from home, it will come up on your smartphone to say 'do you want to turn your heating off because you're not there'. 


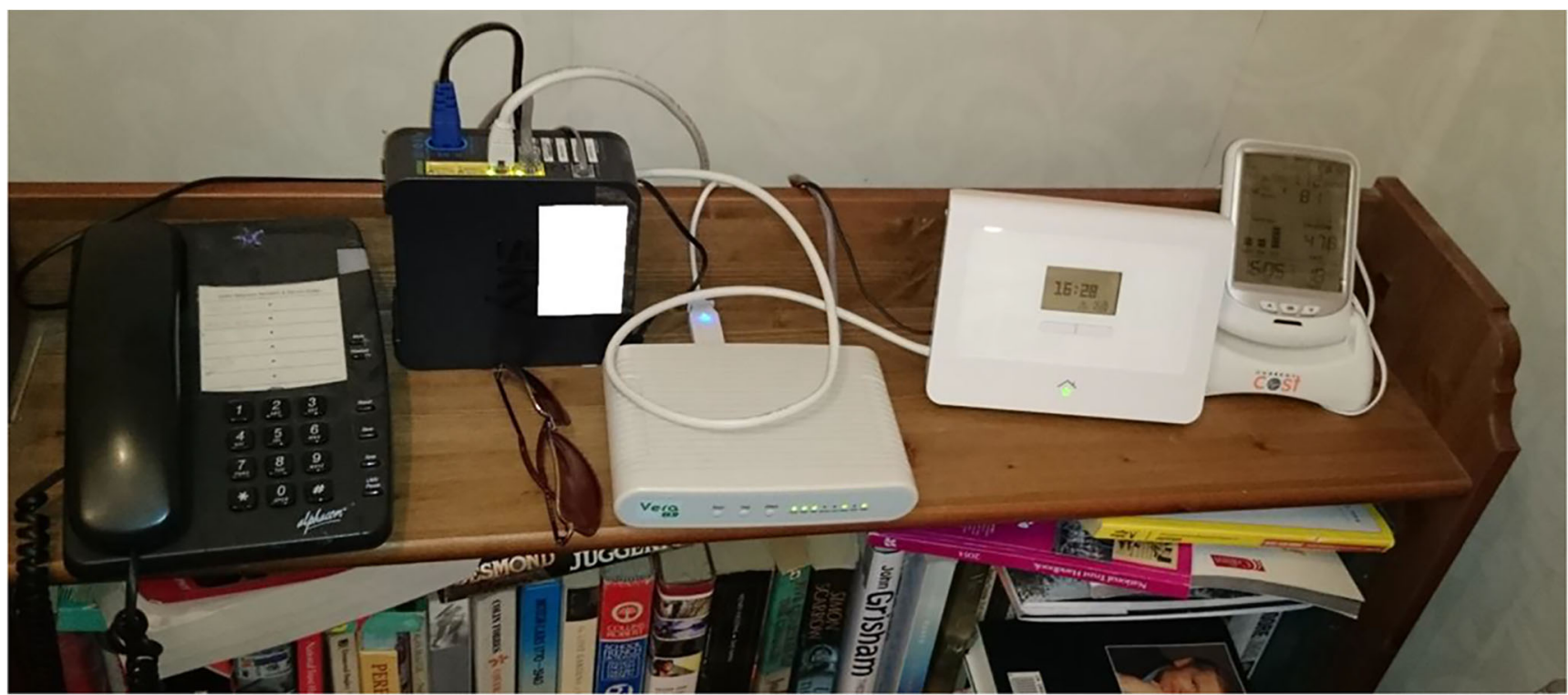

Fig. 2 After a while, they become 'just another bit of kit'

However, in some houses, even the basic capabilities such as schedules and zonal control were seldom used. FH7 described how her house structure and occupancy (2 adults and 2 children) explained why they had opted-out of the Hive system at the beginning of the study, why they had only made limited use of RWE system during the year, and had asked for it to be removed at the end of the trial: 'we don't have rooms that we don't use because there's only a bathroom and the three bedrooms upstairs and only these two rooms down here, it's not like we've got loads of rooms that aren't being used where we'd need to turn the heating off... so that works fine for us, just using the thermostat in the lounge'. With similar demographics, MH2 explain why they hadn't used motion detectors to automate the heating system: 'we're fully occupied anyway, we've got four people in a three bedroomed house, so it's hard to imagine why... we'd want to get the occupancy sensors to do something automatic'.

The retired couple in house 18 explained that advanced scheduling features are of limited use for occupants with regular routines: therefore, they needed only simple heating settings. 'We sort of lowered the temperature in the morning and upped it in the afternoon' (FH18). On the contrary, for FH11, the technology did not fit within her lifestyle due to the lack of a predictable routine: 'I don't have one [daily routine], you know, It just depends what happens. I have about three things that are regular each week, the rest of the time could be anything, so... technology doesn't quite fit that in a way'.

One challenge anticipated by households was that children could tamper with the systems - this happened in four houses, as illustrated by FH7: 'the kids loved it that they could change the numbers on [the radiator valves]'. In two other houses, the problem was with pets: in H17, a rabbit chewed through a power cord switching the whole system off, and FH10 reported that they 'had more problem with the cat actually! She kept changing [the temperature settings on the radiator valve] in the bathroom! She kept rubbing her head against it!'

Finally, households with frugal lifestyles found it hard to justify the use of the technology in order to bring about minimal reductions in energy usage. Those who already put effort into energy saving were sceptical that SHT could be of much benefit. FH7 gives an example: 'this morning I cooked a chicken, the sun was shining, so I thought right I'll put it in the oven now, so that I use the energy from the solar panels. So yeah, I think... I'd be surprised if we could get our bills down much more'.

\section{Discussion}

The results from this study show that many of the participants' expectations of benefits to be obtained from the SHT (preinstallation phase) were met after living with it for approximately a year. These benefits included improved comfort and convenience, in line with previous research $[2,3]$. The majority of householders achieved the expected convenience of controlling the heating system from a computer or smartphone. They also reported the comfort of precise temperatures in different rooms, be it to match specific preferences for different occupants or to optimise the heat output by performing a zonal control of the system to match time of occupancy of each room. The convenience of zonal control prevented the need to manually turn radiators off and back on again at different times of the day, which is a behaviour sometimes recommended as a way to save energy [20].

However, it was clear that the extent to which initial expectations regarding benefits were actually met was dependent on 
factors relating to lifestyle, household makeup, and house characteristics. Families with varied routines in large houses had more variability in terms of their heating demand schedules and zones - individuals are in different areas of the house at different times of the day. This variability (whether predictable or unpredictable) presented an opportunity for savings using occupancy-sensitive SHT and enabled initial expectations to be fulfilled in terms of comfort, convenience, control, and remote management. This meeting of initial expectations was also evident for a sole occupant working non-regular shifts who benefited from automated triggers to turn the heat on or off according to her geographic location.

By contrast, there was a greater disappointment in relation to initial expectations for occupants with fixed routines and regular schedules: they were relatively unsatisfied with the added value derived from the SHT. By way of example, a retired couple with consistent daily routines and using only a small number of rooms in their house found the reality of usage did not match with their initial expectations at the installation phase. A regular boiler program provided them with the functionality they required. A similar example of the reality not matching initial expectations was found for a family with young children in a small house - after installation, they realised that the flexibility and automation that a smart system offers were not providing much-added value since most rooms in the house were fully occupied according to regular schedules.

The introduction of the SHT can affect the internal relations of power and control within families at different levels [17, 18]. Our results show that, in H17, the male took charge of the systems as usual, given that the female is 'terrified' of technology. However, in $\mathrm{H} 21$, the female was responsible for managing it, just because she was the only one that happened to be available during the scheduled installation. In $\mathrm{H} 5$, the introduction of the technology exacerbated existing power relations: both parents centralised the control of the systems making sure children could not alter it from within the home. This potential impact on power and control had not been raised at the installation phase.

The barriers to the introduction of SHT presented here resonate with what has already been documented in the literature $[6,24]$. The majority of households (as they anticipated) reported that they experienced hardware and software problems during the year. Similarly to what was reported by Bly et al. [25], there was sometimes a mismatch between what households expected to be able to do and the specific device capabilities and features available to them. In this study, in some cases, the features were present but complicated to access. Simple automation of lights was not offered as a default setting, requiring advanced setup and programming of triggers, which frustrated most users.

In a work setting where software is used frequently, users may interact with increasing advanced functionalities as familiarity increases [26, 27]. In contrast, in the domestic setting, many aspects of SHT are used sporadically in a 'set and forget' mode. This limits the possibilities for familiarisation with new features. Most householders did not commit the time needed to familiarise themselves with the full set of functionality offered. In some occasions, a 'minimising effort' strategy was used by householders in order to accommodate the new technology into their homes. Householders tended to settle at a baseline level of interaction which they felt comfortable with, for example, some ended up using the SHT in a similar way to how they used their previous systems, thus neglecting the more advanced features available.

Similarly to literature that reports that users find heating systems too complex [28], difficult to operate [29], and prone to user error [30], the difficulty managing the systems was voiced by the majority of households. However, some issues that were clear obstacles at the time of implementation were subsequently overcome. For example, MH5 dedicated time and effort to configure the systems to suit their needs, and MH1 bought a smartphone and learned how to use it to be able to control the systems. FH11 persevered and found out that a computer system could, in fact, facilitate the process of changing settings on all radiator valves, including the hard-toreach, from a single screen at once. These examples suggest that where users anticipate significant value through use they are more likely to strive to overcome usability issues - i.e. the explicit or implicit cost-benefit assessments that have long been recognised as influencing consumers [31, 32], or the 'trade-off or weighing up of the benefits and sacrifice' highlighted more recently by Zauner [33].

In studies of new technology, Karapanos et al. [34] and Kujala et al. [35] reported that initial experiences of smartphone users are high in hedonic aspects such as positive aesthetics, novelty, and overall user experience. Our participants, in contrast, were concerned about poor aesthetics and obtrusiveness of the smart home devices prior to their introduction into their homes, and this preconception was also highlighted by Wilson et al. [4]. Whereas smartphone users' accounts of attractiveness over time show deterioration (reduction of a positive construct), our households reported that concerns of obtrusiveness generally diminished over time (reduction of a negative construct). By the end of this study, householders were generally no longer concerned about the aesthetics and intrusiveness of devices. After an extended period, households stopped noticing the physical devices, which were usually placed side-by-side along with other existing technology or were just a contributor to 'clutter' in specific areas of the house.

The current study evaluated the interactions with off-theshelf SHT, which had been in the market for a few years. Although technology progresses, its use and subsequent acceptance or rejection are influenced by the match between expectations and experience. As well as the issue of 
expectations vs. reality, the actual difficulties faced by our participants are consistent with users of recent technology and other types of SHT such as internet-connected cameras, smart lights, or smart thermostats [36, 37]. Recent developments in SHT, for example with the Nest thermostat, are pursuing the simplification of user interactions through algorithms that learn occupancy patterns and energy use [38]. However, these systems present drawbacks similar to the ones reported in the current study, including limited feedback on energy use [39], poor predictions [40], lack of actionable recommendations, and diminishing user engagement over time [41]. None of these had been highlighted as potential concerns by participants at the installation phase but became salient after households experienced the systems for 1 year.

\subsection{Recommendations for design}

Based on this study, there are various recommendations relating to the broader adoption of SHT, as follows:

The design of SHT needs to be simplified still further. In particular, they must work 'out of the box', with core functionality accessible with no technical input. The usability of additional configuration must be improved, so that the 'curious but technically cautious' householder can achieve (practically and subjectively) a degree of control over its operation. Finally, the technically adventurous expect to be able to 'fiddle' with the technology, and access to more complex modes of operation is needed to satisfy these types of householders.

For longer-term satisfaction, we indicate that the design of SHT needs to tackle the issues that only arise when products are used in 'real' home environments (rather than focussing on marketing-driven aesthetics). Examples include noisy motorised components and bright LED indicators which can be very intrusive at night or in tranquil home environments, controls that are easily interfered with by children or pets, and batteries that need replacing regularly. A home-based testing element within a product development cycle will identify issues that need to be tackled.

Better consumer advice at the purchase and installation phases is needed, to ensure that initial householder expectations are realistic and products are tailored to household needs. A decision support 'tool' or service is needed to help consumers understand whether/how they could benefit from SHT. This tool should take into account the type of house, the household makeup, and the lifestyle structures to demonstrate the added value (or lack of) generated by different functionality. The homes that will derive the greatest benefit from the 'smart' aspect can be targeted. To ensure that expectations and demonstrations of added value are personal and tangible, tailored 'visions of the future' scenarios can be used to portray what the freedoms and conveniences [42] might be for particular households.
Minimising the potential disruption of installation is a key opportunity to encourage uptake. 'Windows of opportunity' arise during periods of renovation, for example, the installation of generic network cabling, and these can be capitalised on to tailor smart home installations and reduce their cost and disruption. It is also possible to use the increased awareness of instrumental benefits (e.g. energy demand reduction) during the installation phase to promote other effective measures. An example would be helping householders understand that zonal heating should be combined with less visible enhancements such as improved insulation. Households may require advice from external advisors to help make sense of the data, ideally situated in the context of use [20].

The final recommendation relates to the need for an installation 'service' that helps householders make good decisions about technologies and their installation and configuration. The installation phase needs to be a negotiated act, with householders actively involved in key decisions. Installers need to be able to better guide householders towards SHT that will add value within their lives and help them configure them to work most effectively.

\section{Conclusion}

In this study, we gathered the expected benefits and anticipated challenges before the introduction of smart home technology (SHT) and evaluated the situations in the same households 1 year later. The contribution of this article comes with the longitudinal analysis of whether expectations were met, whether challenges persisted over time and whether household eventually accepted or rejected the technology.

Results showed that approximately a year after installation, many of the initial expectations of the benefits were met, including thermal comfort, operational convenience, fine control of temperature in zones, remote control, and feedback on energy use. When expectations were not met, this was usually due to the effort required to set up and control systems, rather than the lack of functionality. Those who demonstrated technological proficiency generally persevered in controlling how the technology worked in line with their expectations. However, less technically adept householders who found the installed systems relatively complex kept systems operating on basic modes only or asked for the systems to be removed. Out of the 20 houses, three of them wanted to have some of the SHT uninstalled and roll back to previous arrangements. $\mathrm{H} 7$ and $\mathrm{H} 8$ asked to have the RWE kit removed, and $\mathrm{H} 20$ gave up the Hive system. By the end of the project, five of the other households had sourced additional equipment to complement their existing SHT. Therefore, although not all expectations at the installation phase had been met, the actual decisions of the households were overwhelmingly to continue using the SHT. 
The structures of domestic life clearly influenced the usefulness and level of adoption of the SHT. There turned out to be limited usefulness for (1) households with very regular routines, (2) families living in small houses with most rooms occupied, or (3) those with frugal lifestyles. However, households with varied occupancy of rooms, larger houses, and varying daily schedules largely obtained what they expected in relation to comfort, convenience, control, or management. Expectations at the purchase/installation phases need to be set accordingly; otherwise, householders will be disappointed.

The majority of the challenges anticipated by participants at the beginning of the project did actually materialise - for example, incompatibility of pre-existing hardware and software, reliability of devices, and complexity of use. Although technology improvements are reducing the impact of these issues, there needs to be further focus on improving the installation (and especially retrofit) of SHT into existing homes in order to obtain the functional, instrumental, and sociotechnical benefits that can arise.

Funding information This work was financially supported by the Engineering and Physical Sciences Research Council (EPSRC): grant number EP/K002457/1. Further details of the project, including how to access project data, can be found here: https://www.refitsmarthomes.org/

\section{Compliance with ethical standards}

Conflict of interest The authors declare that they have no conflict of interest.

Open Access This article is distributed under the terms of the Creative Commons Attribution 4.0 International License (http:// creativecommons.org/licenses/by/4.0/), which permits unrestricted use, distribution, and reproduction in any medium, provided you give appropriate credit to the original author(s) and the source, provide a link to the Creative Commons license, and indicate if changes were made.

\section{References}

1. Harper R (2003) Inside the smart home. Springer, London

2. Balta-Ozkan N, Davidson R, Bicket M, Whitmarsh L (2013) Social barriers to the adoption of smart homes. Energy Policy 63:363-374. https://doi.org/10.1016/j.enpol.2013.08.043

3. Cook DJ (2012) How smart is your home? Science (80- ) 335: 1579-1581. https://doi.org/10.1126/science. 1217640

4. Wilson C, Hargreaves T, Hauxwell-Baldwin R (2017) Benefits and risks of smart home technologies. Energy Policy 103:72-83. https:// doi.org/10.1016/j.enpol.2016.12.047

5. Brush AJB, Lee B, Mahajan R, et al (2011) Home automation in the wild: challenges and opportunities. In: Proceedings of the SIGCHI Conference on Human Factors in Computing Systems - CHI'11. pp 2115-2124

6. Wilson C, Hargreaves T, Hauxwell-Baldwin R (2015) Smart homes and their users: a systematic analysis and key challenges. Pers Ubiquit Comput 19:463-476. https://doi.org/10.1007/s00779-0140813-0

7. Rodden T, Benford S (2003) The evolution of buildings and implications for the design of ubiquitous domestic environments. Proc
Conf Hum factors Comput Syst - CHI '03 9. https://doi.org/10. $1145 / 642614.642615$

8. Tolmie P, Crabtree A, Egglestone S et al (2010) Digital plumbing: the mundane work of deploying UbiComp in the home. Pers Ubiquit Comput 14:181-196. https://doi.org/10.1007/s00779-0090260-5

9. Tendedez H, Widdicks K, Hazas M (2018) Planning for the things you can't plan for: lessons learned from deployments in the home. Interactions 26:52-57. https://doi.org/10.1145/3292019

10. Hazas M, Friday A, Scott J (2011) Look back before leaping forward: four decades of domestic energy inquiry. IEEE Pervasive Comput 10:13-19. https://doi.org/10.1109/MPRV.2010.89

11. Mennicken S, Vermeulen J, Huang EM (2014) From today's augmented houses to tomorrow' $\mathrm{s}$ smart homes: new directions for home automation research. In: UbiComp '14 Proceedings of the 2014 ACM International Joint Conference on Pervasive and Ubiquitous Computing. pp 105-115

12. Venkatesh V, Goyal S, Information M (2010) Expectation disconfirmation and technology adoption: polynomial modeling and response surface analysis. MIS Q 34:281-303. https://doi.org/10. 2307/20721428

13. Kujala S, Mugge R, Miron-Shatz T (2017) The role of expectations in service evaluation: a longitudinal study of a proximity mobile payment service. Int J Hum Comput Stud 98:51-61. https://doi.org/ 10.1016/j.ijhcs.2016.09.011

14. Hassenzahl M (2010) Experience design: technology for all the right reasons. Synth Lect Human-Centered Informatics 3:1-95. https://doi.org/10.2200/S00261ED1V01Y201003HCI008

15. Venkatesh V, Brown SA (2001) A longitudinal investigation of personal computers in homes: adoption determinants and emerging challenges. MIS Q 25:71-102 https://doi.org/10.2307/3250959

16. Hargreaves T, Wilson C, Hauxwell-Baldwin R (2018) Learning to live in a smart home. Build Res Inf 46:127-139. https://doi.org/10. 1080/09613218.2017.1286882

17. Berger A, Bischof A, Totzauer S, et al (2019) Sensing home: participatory exploration of smart sensors in the home. In: Internet of Things. pp 123-142

18. Hargreaves T, Hauxwell-Baldwin R, Coleman M, et al (2015) Smart homes, control and energy management: how do smart home technologies influence control over energy use and domestic life? In: European Council for an Energy Efficient Economy (ECEEE) Summer Study. Toulon/Hyères, France, pp 1021-1032

19. Burrows A, Mitchell V, Nicolle C (2016) Let's spend some time together. Int J Mob Hum Comput Interact 8:69-82. https://doi.org/ 10.4018/IJMHCI.2016040104

20. Fischer JE, Crabtree A, Rodden T, et al (2016) "Just whack it on until it gets hot": Working with IoT data in the home. In: Proceedings of the $2016 \mathrm{CHI}$ Conference on Human Factors in Computing Systems - CHI '16. ACM Press, San Jose, California, USA, pp 5933-5944

21. Braun V, Clarke V (2006) Using thematic analysis in psychology. Qual Res Psychol 3:77-101. https://doi.org/10.1191/ 1478088706qp063oa

22. Oliveira L, May A, Mitchell V et al (2015) Pre-installation challenges: classifying barriers to the introduction of smart home technology. Proc EnviroInfo ICT Sustain 2015:9. https://doi.org/10. 2991/ict4s-env-15.2015.14

23. Robson C (2011) Real World Research: a resource for users of social research methods in applied settings, 3rd edn. John Wiley \& Sons Inc, UK

24. Edwards WK, Grinter RE (2001) At home with ubiquitous computing: seven challenges. In: UbiComp '01 Proceedings of the 3rd international conference on Ubiquitous Computing. pp 256-272

25. Bly S, Schilit B, McDonald DW et al (2006) Broken expectations in the digital home. In: $\mathrm{CHI}$ '06 extended abstracts on Human factors in computing systems - CHI EA '06. ACM Press, New York, p 568 
26. Shneiderman B, Plaisant C (2010) Designing the user interface: strategies for effective human-computer interaction, 5th edn. Addison-Wesley, Boston

27. Mendoza V, Novick DG (2005) Usability over time. In: Proceedings of the $23 \mathrm{rd}$ annual international conference on Design of communication documenting $\&$ designing for pervasive information - SIGDOC '05. ACM Press, New York, p 151

28. Peffer T, Pritoni M, Meier A et al (2011) How people use thermostats in homes: a review. Build Environ 46:2529-2541. https://doi. org/10.1016/j.buildenv.2011.06.002

29. Meier A, Aragon C, Peffer T et al (2011) Usability of residential thermostats: preliminary investigations. Build Environ 46:18911898. https://doi.org/10.1016/j.buildenv.2011.03.009

30. Wall S, Healy F (2013) Usability testing of smarter heating controls - a report to the Department for Energy and Climate Change. UK, London

31. Sweeney JC, Soutar GN (2001) Consumer perceived value: the development of a multiple item scale. J Retail 77:203-220. https://doi.org/10.1016/S0022-4359(01)00041-0

32. Zeithaml VA (1988) Consumer perceptions of price, quality, and value: a means-end model and synthesis of evidence. J Mark 52:222. https://doi.org/10.1177/002224298805200302

33. Zauner A, Koller M, Hatak I (2015) Customer perceived valueconceptualization and avenues for future research. Cogent Psychol 2:1-17. https://doi.org/10.1080/23311908.2015.1061782

34. Karapanos E, Zimmerman J, Forlizzi J, Martens J (2009) User experience over time: an initial framework. In: Proceedings of the 27th international conference on Human factors in computing systems - CHI 09. ACM Press, New York, New York, USA, p 729

35. Kujala S, Roto V, Väänänen-Vainio-Mattila K et al (2011) UX curve: a method for evaluating long-term user experience. Interact Comput 23:473-483. https://doi.org/10.1016/j.intcom.2011.06.005
36. He W, Martinez J, Padhi R, et al (2019) When smart devices are stupid : negative experiences using home smart devices. In: SafeThings 2019 - IEEE Workshop on the Internet of Safe Things. San Fancisco, CA, USA, p 6

37. Fuentes C, Porcheron M, Fischer JE, et al (2019) Tracking the consumption of home essentials. In: Proceedings of the 2019 CHI Conference on Human Factors in Computing Systems - CHI '19. ACM Press, Glasgow, UK, pp 1-13

38. Yang R, Newman MW (2013) Learning from a learning thermostat: lessons for intelligent systems for the home. In: Proc 2013 ACM Int Jt Conf Pervasive ubiquitous Comput (UbiComp 2013), pp 93102. https://doi.org/10.1145/2493432.2493489

39. Promann M, Brunswicker S (2017) Affordances of eco-feedback design in home energy context. In: Proceedings of the 33rd Americas Conference on Information Systems (AMCIS). Boston, MA, USA, pp 1-10

40. Li Y, Yan Z, Chen S, et al (2019) Operation strategy of smart thermostats that self-learn user preferences. IEEE Trans Smart Grid, pp 1-1. https://doi.org/10.1109/TSG.2019.2891508

41. Yang R, Newman MW, Forlizzi J (2014) Making sustainability sustainable: challenges in the design of eco - interaction technologies. In: SIGCHI Conference on Human Factors in Computing Systems. pp 823-832

42. Keen PGW, Mackintosh R (2001) The freedom economy: gaining the M-commerce edge in the era of the wireless Internet. Osborne/ McGraw-Hill

Publisher's note Springer Nature remains neutral with regard to jurisdictional claims in published maps and institutional affiliations. 